(This is a penultimate version. The final version is due to be published in Inquiry. Please refer to the published version.)

\title{
Credal sensitivism: threshold vs. credence-one
}

\author{
Jie Gao \\ Zhejiang University
}

\begin{abstract}
According to an increasingly popular view in epistemology and philosophy of mind, beliefs are sensitive to contextual factors such as practical factors and salient error possibilities. A prominent version of this view, called credal sensitivism, holds that the context-sensitivity of belief is due to the context-sensitivity of degrees of belief or credence. Credal sensitivism comes in two variants: while credence-one sensitivism (COS) holds that maximal confidence (credence one) is necessary for belief, threshold credal sensitivism (TCS) holds that belief consists in having credence above some threshold, where this threshold doesn't require maximal confidence. In this paper, I argue that COS has difficulties in accounting for three important features about belief: i) the compatibility between believing $p$ and assigning non-zero credence to certain error possibilities that one takes to entail not- $p$, ii) the fact that outright beliefs can occur in different strengths, and iii) beliefs held by unconscious subjects. I also argue that TCS can easily avoid these problems. Finally, I consider an alleged advantage of COS over TCS in terms of explaining beliefs about lotteries. I argue that lottery cases are rather more problematic for COS than TCS. In conclusion, TCS is the most plausible version of credal sensitivitism.
\end{abstract}

Keywords: belief; credence; doxastic sensitivism; credal sensitivism; credence-one view; threshold view

\section{Introduction}

It seems nearly a platitude that contextual factors can influence our dispositions to form, revise or retain certain beliefs. We are not unfamiliar with the experience that in high stakes situations we often refrain from believing things that we used to believe when stakes were low. For example, you first believe that the radio is playing a Sibelius quartet and are tempted to make a remark like "This Sibelius quartet is well performed." But upon realizing the risk of incurring disapproval from your companion who is knowledgeable about music and very critical, you may find your conviction that what is being played is a Sibelius quartet shaken and decide to remain silent. Likewise, we tend to lose beliefs when certain error possibilities are made salient. For instance, at the zoo you form a belief that the animal behind the fence is a zebra, but when your 
partner raises the possibility that some zebras in the zoo might have been replaced with cleverly painted mules, you may start doubting whether you are looking at a real zebra.

Let's label doxastic sensitivism the cluster of views that accommodate the above observations by holding that whether one believes a proposition $p$ depends on or is affected by contextual factors such as practical factors and salient error-possibilities. Doxastic sensitivists have defended their views on various grounds. Brian Weatherson (2005), Dorit Ganson (2008), and Jeremy Fantl \& Matthew McGrath (2009) have advanced specific functionalist accounts of belief entailing doxastic sensitivism. According to these accounts, believing something involves having certain behavioural dispositions that are influenced by contextual factors. One of these dispositions is being willing to act on the believed proposition (viz., as if that proposition was true). Since whether one is willing to act on $p$ is partly influenced by contextual factors, these accounts imply that belief is sensitive to shifts of context. Another version of doxastic sensitivism endorsed by Jennifer Nagel $(2008,2010)$ explores psychological (rather than metaphysical) aspects of belief. Drawing upon a substantial body of empirical studies, Nagel shows that contextual settings play an important role in determining the kind and degree of cognitive effort one is willing to allocate in order to reach a settled opinion. These data indicate a systematic sensitivity of belief regulation to contextual factors. Moreover, Daniel Greco (2015), Dylan Dodd (2017) and Roger Clarke (2018) have defended the context-sensitivity of belief by appealing to an analogy between belief and sincere assertion. Conversations are commonly conceived as taking place against a background of mutual presuppositions, the so-called 'common ground'. Just as the common ground to which interlocutors restrict their attention constitutes the context for conversation, the set of error possibilities to which a believer restricts her attention constitutes the context for her doxastic attitudes. As the context for assertion evolves with the common ground, what it takes for one to count as believing that $p$ evolves with shifts of doxastic context. ${ }^{1}$

Almost all doxastic sensitivists so far agree that full belief is constituted by certain degrees of belief (credences). Disagreements amongst these philosophers arise with respect to the following two issues:

i) Does full belief require maximal degree of credence?

ii) Are credences also context-sensitive?

On the one hand, some doxastic sensitivists including Weatherson, Ganson and Fantl \& McGrath provide negative answers to both questions. ${ }^{2}$ Concerning the first question, they hold the threshold view of belief, according to which belief consists in having a degree of credence above a certain threshold but falling short of maximal confidence (i.e. credence one). ${ }^{3,4}$ Concerning the second question, they endorse threshold sensitivism, according to which the context-sensitivity of

\footnotetext{
${ }^{1}$ Still another variant of doxastic sensitivism is defended by Bach (2005).

2 See also Kyburg (1983) and Sturgeon (2008).

${ }^{3}$ With threshold view here I mean any view of outright belief admitting a threshold of credence below one, no matter whether this threshold is context-sensitive or not. This notion of 'threshold view' is wider than that discussed by Weatherson (2005). [acknowledgment]

${ }^{4}$ Nagel also expresses her sympathy for the threshold view (Nagel 2010: 417-18).
} 
belief is due to a corresponding sensitivity of the threshold on credence necessary for belief, not to a sensitivity of credence itself.

On the other hand, Clarke (2013), Greco (2015) and Dodd (2017) defend positive answers to both questions. They advocate the credence-one view, which says that belief requires credence one or maximal confidence. On their views, since the threshold on credence necessary for belief is fixed (i.e. one), beliefs cannot be context-sensitive unless credences are as well. Let's label this position credence-one sensitivism (henceforth COS). Call credal sensitivism the more general view according to which credences are context-sensitive, and it is their context-sensitivity that explains the context-sensitivity of belief. COS is a specific version of credal sensitivism.

In an attempt to adjudicate the second question above, in Gao (2019) I have argued that a wide range of empirical and intuitive data favour credal sensitivism over threshold sensitivism. In this paper, I shall assume that my conclusions in Gao (2019) are correct, and thus that credal sensitivism is right. My goal is to advance the dispute, internal to credal sensitivism, concerning whether full belief requires maximal credence or not. I shall compare two credal sensitivist positions: COS and threshold credal sensitivism (henceforth TCS). The peculiar feature of TCS is that, while this view holds that the context-sensitivity of belief is due to the context-sensitivity of credence, it denies that belief requires maximal credence and endorses the threshold view-TCS answers NO to question (i) and YES to question (ii). I shall assess these two views given their explanatory power in accommodating a series of desiderata of belief. My conclusion is that TCS fares better than COS in accommodating these desiderata. This constitutes prima facie evidence for the further conclusion that TCS is the most plausible version of credal pragmatism.

Here is the structure of the paper. In $\$ 2$ I introduce in more detail my favourite version of TCS and the version of COS endorsed by Clarke and Greco. In \$3, I argue that TCS is better placed than COS in accounting for three important features about belief: i) the compatibility between believing that $p$ and assigning non-zero credence to certain possibilities that one takes to entail not- $p$, ii) the fact that outright beliefs can be held in different strengths, and iii) beliefs held by unconscious subjects. In $₫ 4$, I consider an alleged advantage of COS over TCS: that COS fares better than TCS in explaining beliefs about lotteries. While I think that TCS has the resources to accommodate lottery cases, I shall argue that under closer inspection such cases are more problematic for COS than TCS.

Before proceeding further, let me be clear from the outset on the scope of this paper. My goal here is restricted to the comparative question of which amongst credal sensitivism accounts is better. It is not an aim of the present paper to provide a full-fledged defence of credal sensitivism. Thus I will not be concerned, for example, with the advantages and problems that credal sensitivism has compared to its alternatives. These issues have already been discussed elsewhere. ${ }^{5}$ Those rejecting credal sensitivism or withholding opinion on the matter are free to read my conclusion as merely conditional: amongst versions of credal sensitivism, the more plausible one is TCS.

\footnotetext{
${ }^{5}$ Besides the arguments provided by Clarke and Greco, other advantages of credal sensitivism include its ability to explain a series of empirical and linguistic data [Author a]. The main problem for credal sensitivism concerns the tension between the contextual sensitivity of doxastic attitudes and evidentialist standards of epistemic rationality governing these attitudes. For responses, see [Author a, \$3] and Clarke $(2013, \$ 6)$.
} 
That said, it is worth observing that at least some of the arguments proposed in $₫ 3$ and $\$ 4$ have a wider scope, insofar as they address the more general debate between the threshold view and the credence-one view. As acknowledged by Clarke and Greco, the credence-one view is

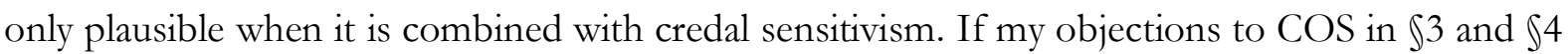
are on the right track, the only plausible form of credence-one view would be undermined, and the threshold view would emerge as the final winner from the debate.

\section{TCS and COS}

In this section, I will first introduce the specific version of TCS that I endorse $(\$ 2.1)$ and the version of COS defended by Clarke (2013) and Greco (2015) (\$2.2). I will then highlight the crucial differences between TCS and COS (\$2.3).

\subsection{TCS}

TCS is constituted by the conjunction of the following two positions:

(The Threshold View) Belief consists in having credence above some threshold falling below probability one.

(Credal Sensitivism) Credences are context-sensitive, and the contextsensitivity of credence explains the context-sensitivity of belief.

Let me introduce three important remarks about TCS. First, traditionally, the threshold view has been taken to commit to the metaphysical reduction of belief to credences. The threshold view that I consider here is neutral on reductivism. TCS merely says that believing $p$ involves having credences above a certain threshold and leaves it open whether full belief is ontologically derivative from credences. Thus, the view is also compatible with dualist approaches claiming that belief is metaphysically distinct from credence. ${ }^{6}$

Second, the contextual factors relevant to credal sensitivism include the set of possibilities one takes seriously (or live/salient possibilities) as well as various perceived practical factors. As for the practical factors, in Gao (2019) I have suggested that they could be divided into two sets given their effects on normal people's doxastic attitudes. On the one hand, caution-oriented factors have the effect of leading one to form or retain beliefs only on the basis of more evidence and/or more cognitive efforts. Examples are high costs of being wrong, significant benefits of achieving accurate conclusions, the availability of further evidence, etc. On the other hand, rushoriented factors have the effect of leading one to believe on the basis of less evidence and fewer cognitive efforts. Examples are considerable benefits of having a settled opinion, remarkable costs of not having a settled view, difficulty of acquiring further evidence, etc. ${ }^{7}$ According to

${ }^{6}$ See e.g., Ross and Schroeder (2014), Jackson (forthcoming), and Weisberg (forthcoming).

7 In the context of the present debate, these factors have been invoked by, for example, Gerken (2011, 2017), Nagel (2008) and appear in psychology works such as Kruglanski and Webster (1991), Kruglanski et al. (1993), Mayseless and Kruglanski (1987) and Webster (1993). 
TCS, credences are sensitive to contextual factors in the following ways: other things being equal, in the formation of a doxastic attitude about a proposition $p$, the more possibilities related to $p$ one considers, and/or the more significant the influence of caution-oriented factors is, the lower the subject's degree of credence in $p$ (normally) is. Conversely, the fewer possibilities related to $p$ one considers, and/or the more significant the influence of rush-oriented factors is, the higher the subject's degree of credence in $p$ (normally) is.

Third, according to my favourite version of TCS, the context-sensitivity of belief and credence is not a constitutive component of the metaphysical nature of these attitudes. Rather, the influence of contextual factors is taken to be a merely psychological fact. In my view, the context-sensitivity of doxastic attitudes characterizes a contingent aspect of the actual regulation of doxastic attitudes of normal subjects (where 'normal' is used in a descriptive, frequentist sense), capturing regularities which are largely predictable by psychology. In this view, in accordance with the traditional picture, both belief and credence are two-place relations between subjects and propositions. ${ }^{8}$ One could conceive alternative versions of TCS that build contextsensitivity into the nature of doxastic attitudes. These views would consider context as part of the metaphysical structure of doxastic attitudes: belief and credence would be relations between subjects, propositions and contexts. For reasons that will become clear below, in this article I shall only consider a psychological version of TCS. However, it is important to keep in mind that this is not the only possible version of the view.

\section{2. $\operatorname{COS}$}

COS is the conjunction of the credence-one view and credal sensitivism. According to Clarke, Dodd and Greco, the space of salient (live) possibilities defines the relevant context to which beliefs are sensitive. ${ }^{9}$ In addition, the context doesn't merely contingently affect the psychology of normal subjects' beliefs, but is built directly into the metaphysical constitution of beliefs. Belief is conceived as a three-place relation between a believer, a proposition and a context. In this picture, in order to answer the question 'Does $S$ believe that $p$ ?', one has to consider also the specific context the subject is in. ${ }^{10}$

According to COS, the space of salient possibilities determines a relevant set of doxastic possibilities over which the credence function distributes. The space of salient possibilities varies depending on the range of salient possibilities and how likely one takes each possibility to be. ${ }^{11}$ If one believes $p$ in a particular context $c, p$ must be true throughout the whole set of salient

\footnotetext{
8 One may add a further temporal value to the relation. What is important is that the potential effects of contextual factors on doxastic attitudes are not part of fundamental metaphysical relations constitutive of doxastic attitudes.

${ }^{9}$ For a similar position, see Norby (2015).

${ }^{10}$ Are there psychological versions of COS? A difficulty in developing this kind of view is that it is unclear how to determine a doxastically relevant space of live error possibilities in a circumstance without making reference to a context. In this respect, according to COS, contexts seem to be essential, constitutive features of belief, not mere contingent psychological aspects of this kind of mental state.

${ }_{11}$ Clarke $(2013,2018)$ only mentions the former mechanism of credence shifts, while Greco (2015, p. 185) also hints at the latter when he says "we think of the common ground as involving presuppositions not just about which possibilities are taken seriously, but also about how likely those possibilities are" (italics original).
} 
possibilities in $c$. In such cases, not-p-possibilities are completely ruled out in $c$, and one's credence in $p$ automatically receives probability one in that context.

Importantly, COS is distinct from what is often labelled the certainty view of belief according to which if one believes that $p$, then one attributes credence one to $p$ across all contexts. The certainty view struggles with a series of notorious problems. As illustrated in Clarke (2013) and Greco (2015), COS nicely avoids almost all of them. Since according to COS believing with the maximal degree of confidence should not be taken to entail certainty across contexts, the view avoids the sceptical consequence that falling short of absolute (non-contextual) certainty in $p$ excludes belief in $p$. Likewise, it also avoids attributing problematic dispositions to someone believing $p$, such as dispositions to judge bets on whether $p$ is true as fair when the stakes are extremely high. Offering a bet could result in changing the context. When the stakes on whether $p$ change, as it should be when a bet is offered, the space of salient alternatives relevant to whether $p$ is also likely to change (e.g. more alternatives become salient) and the confidence in $p$ inevitably lowers.

\subsection{Differences between TCS and COS}

In addition to the obvious difference concerning the degree of credence required for belief, TCS and COS also differ in the following three aspects. First, as already mentioned above, COS takes belief to be a three-place relation between a believer, a proposition and a context. Hence, the context-sensitivity of doxastic attitudes is part of the metaphysical nature of belief: it's part of the nature of belief that it is a kind of mental state individuated by a context. In contrast, TCS takes context-sensitivity to be a purely psychological matter: people's degrees of confidence and beliefs are normally influenced by features of the context, but the latter is not part of the nature of these doxastic attitudes.

Second, COSists and TCSists disagree on the range of possibilities over which the credence function distributes. For COSists, the relevant space exclusively consists of salient possibilities. The relevant set of doxastic possibilities is thus small, variable and presumably tractable for working memory. Since in this picture the context is defined in terms of the space of live possibilities, it trivially follows that the space itself co-varies with the shift of context, as new possibilities become live while others cease to be salient. In contrast, in accordance with the traditional picture, TCSists take the space of relevant possibilities to be consistent across contexts, covering all possibilities that one might take into consideration, not just the salient ones. The credence function is 'global', defined over the whole space of possibilities. The relevant set of doxastic possibilities is large, presumably not tractable for working memory and relatively stable across context shifts. Variable practical factors very rarely bring about changes to the set of possibilities relevant for TCS.

A third important difference, related to the above distinction, is that TCSists and COSists provide different stories about the mechanisms responsible for credence variations. For TCSists, the distribution of probabilities is directly a factor of context-shifts. These probability distribution changes are not mediated by changes in the set of relevant possibilities. For COSists, in addition to re-distributions of credences over the same set of salient possibilities, credence variations can also be (and often are) due to more or fewer possibilities being included in the set of salient possibilities. 
A consequence of this important difference is that the two theories provide different explanations of cases where outright beliefs are gained and lost. For example, consider a case where the subject loses belief that $p$ given an increase in the perceived stakes on whether $p$ is true. According to COS, one loses belief that $p$ in the high-stakes situation because some possibility entailing not- $p$ has been added to the set of live possibilities and as a result the subject's credence in $p$ falls under probability one. On the contrary, according to TCS, the shift from a low- to a high-stakes situation has the effect that the subject assigns a lower probability to $p$ to such a degree that the subject's credence in $p$ falls below the threshold of credence necessary for belief-for example, the credence in $p$ decreases from 0.98 to 0.9 , where the threshold for belief is 0.95 .

\section{TCS vs. COS}

In this section, I will evaluate TCS and COS against three important features of belief: i) the compatibility between believing that $p$ and assigning non-zero credence to certain error possibilities that one takes to entail not- $p$ (\$3.1), ii) the fact that outright beliefs can occur in different strengths (\$3.2), and iii) beliefs held by unconscious subjects (\$3.3). I will argue that while COS has difficulties in accommodating these features, TCS does not.

\subsection{Belief and non-ignored possibilities}

The first feature of belief concerns cases in which one believes $p$ in spite of assigning minimal positive credence to certain possibilities that one takes to entail not- $p$. Two types of error possibility are relevant here: far-fetched and non-far-fetched.

\subsubsection{Belief and far-fetched possibilities}

Let's first consider cases involving far-fetched possibilities. These are possibilities that from the subjective perspective are utterly unlikely to happen. Typical examples are sceptical scenarios. For instance, the possibility that you are a brain embedded in a vat of nutrients and wired to a sophisticated computer program that generates perceptual experiences about the outside world, or the possibility that all your perceptual experiences and memories are actually induced by a powerful evil demon. Far-fetched possibilities also include extremely bizarre scenarios. Here are some examples: i) the possibility that within a short while, the particles belonging to the surface of your desk remain more or less unmoved but the material inside the desk unfolds in a bizarre enough way that the system no longer counts as a desk (Hawthorne 2004: 4-5); ii) that the matter in your car has spontaneously reorganized in the form of a giant lizard (MacFarlane 2005: 201); and iii) that the egg I just dropped on the floor will suddenly jump back up into my hand and be whole again, as if I never had dropped it (Dodd 2017: 4607). When we are forced to acknowledge the existence of such possibilities, we do at least sometimes attribute some positive probability to such far-fetched possibilities, even if it might be a minimal value.

According to COS, if one believes $p$ one's credence in $p$ is one and credence in possibilities that one takes to entail not- $p$ is zero. In other words, if one assigns any positive credence to 
possibilities that one takes to entail not- $p$, no matter how low, according to COS one does not believe $p$. Now it seems clear that there are cases where one becomes aware of a certain farfetched error possibility and thereby attributes a non-zero chance to its happening. Nonetheless, entertaining such error possibilities doesn't seem to affect one's outright belief. Consider cases where one is aware of the possibility of a sceptical scenario. Presumably, upon learning about the possible occurrence of the scenario, one registers that possibility. For example, one takes as possible that our cognitive systems might be embedded in a virtual simulation. In such a case, it is possible that one forms a sceptical attitude towards the reality of the external world and drops her ordinary beliefs. But it is also possible (and indeed pretty common) that one does not revise her ordinary beliefs while at the same time being mindful of the possibility of the sceptical scenario. Such a possibility has been recognized by several philosophers. For example, according to Jonathan Adler:

[E]ven when a counter-possibility is accepted (regarded as relevant), in radical cases the persuasion is often half-hearted. The student who is moved by your dreaming argument to sincerely deny that he knows that he is in the classroom does not cease to believe that he is in the classroom. (2012: 264)

It is natural to interpret the student in Adler's quote as one who understands the argument and recognizes the sceptical scenario as an open possibility but leaves her ordinary beliefs intact. In this case, the student assigns a positive credence to the possibility of that scenario, for she cannot really deny its possibility no matter how improbable she thinks it is, even though she deems the possibility as merely idle. The same happens in other cases where one maintains her ordinary belief but at the same time cannot dispel some bizarre possibility. ${ }^{12}$

Apparently, COS delivers the wrong prediction in this type of cases. According to COS, as long as one recognises error possibilities that one takes to be incompatible with $p$, no matter how low the credence one assigns to those possibilities, one's credence in $p$ would be less than one, and hence one would not count as believing $p$. COS can accommodate cases involving losses of ordinary beliefs when one is fully persuaded by arguments for scepticism, but it cannot explain cases where one's ordinary beliefs manage to survive sceptical considerations.

Here COSists might bite the bullet and question the compatibility of maintaining ordinary beliefs and entertaining far-fetched error possibilities at the same time. In this regard, Dodd (2017: 4613-4) emphasizes the infelicity of asserting sentences such as 'the egg I just dropped on the floor will stay on the floor (it will not suddenly jump back up into my hand and be whole again) but it is possible that it won't'. Assuming that full assertions are the expressions of outright beliefs, this (alleged) infelicity would indicate the incompatibility of maintaining an ordinary belief that $p$ while at the same time entertaining far-fetched error possibilities that not- $p$.

In response, I must admit that I find the above and similar assertions perfectly felicitous. Other assertions having a similar syntactical structure, such as those taken to exemplify the Moore's paradox, may sound infelicitous (e.g. 'the bank will be open on Saturday but it is possible that it won't be'). However, the error possibility in most of those paradoxical assertions is practically relevant. By uttering such sentences, the speaker is representing herself as being 'of two minds' on whether she takes $p$ for granted in practical reasoning, and hence as being affected

12 MacFarlane (2005, p. 201) and Gerken (2012, p.141) also suggest that we tend to dismiss very farfetched salient alternatives as epistemically irrelevant. 
by psychological confusion (Dougherty and Rysiew 2009, pp. 128-129). Far-fetched possibilities often do not have this kind of practical significance. Many concessive assertions involving farfetched possibilities do not convey contradictory information about one's practical dispositions. My contention is that, at least to the ears of interlocutors who do not take the far-fetched possibility at issue to be practically relevant, concessive assertions such as 'even though there is a very remote chance that the material inside my desk has unfolded in a bizarre enough way that the system no longer counts as a desk, I still believe that my desk is here under my eyes' can be perceived as perfectly felicitous. This is a clear indication that outright beliefs are compatible with the consideration of far-fetched error possibilities.

Notice also that the claim that we always lose ordinary beliefs every single time we consider a far-fetched error possibility is pretty implausible from an empirical perspective. To rebut this claim, it is sufficient to point to someone who sticks to her ordinary beliefs while also admitting the error possibility. Finding similar examples seems to me extremely easy: I just have to consider by introspection my own beliefs about quantum mechanics as well as the belief that there is a desk in front of me.

\subsubsection{Belief and non-far-fetched possibilities}

Now let's consider cases of belief involving positive credence in non-far-fetched error possibilities. One prominent example concerns one's recognition of the fallibility of beliefforming methods, such as perception, testimony, inference, etc. By 'fallibility', I mean that it is possible to acquire false information by using a certain belief-forming method. Presumably, when one considers the fallibility of a belief-forming method, she attributes a non-zero credence to the possibility of getting false beliefs via that method. Considerations of fallible belief-forming methods constitute salient non-far-fetched error possibilities about beliefs formed via those methods. They are non-far-fetched or mundane possibilities because they are usually not as improbable (in the subjective sense of probability) as radical sceptical scenarios or bizarre possibilities.

It's almost unanimously agreed that we don't take all our belief-forming methods to be infallible. The problem is whether we refrain from forming outright beliefs on the basis of a certain belief-forming method when we consciously acknowledge the fallibility of that method. Imagine that you have just acquired some information from testimony. At the same time, you are contemplating the fallibility of testimony as a method of true beliefs' acquisition. Assume also that there are barely no stakes hanging on the truth of that testimony. Although the possibility that the testimony is wrong is salient to you, you find it somewhat of an overreaction not to accept the testimony you have just received and form a belief on its basis. After all, you also realise that the fallibility of testimony doesn't vanish just because you do not think about it, and normally in similar circumstances you would form a belief with no hesitation. So why should you treat the present situation differently? It is unreasonable to think that, merely in virtue of entertaining the thought that testimony is fallible, I would undermine the possibility of holding a belief that $p$ acquired through testimony. As a matter of fact, this combination of beliefs about 
the fallibility and the content of the testimony seems clearly possible. Indeed, on reflection, I must admit that I myself entertain many similar combinations of doxastic attitudes. ${ }^{13}$

COS, again, delivers the wrong prediction in this type of cases. According to COS, once one recognizes the fallibility of certain belief-forming methods, and one considers that a belief was formed on the basis of that method, one automatically stops having that belief. This is because by recognizing the fallibility of one's belief that $p$, one assigns a non-zero credence to not- $p$, and thereby ceases to have credence one in $p$ and loses that belief.

Furthermore, according to COS, entertaining the fallibility of a certain belief-forming method would result in the suspension, not just of some specific beliefs, but of all beliefs which one takes to be formed by relying on that method. According to Clarke (2013), once it is settled which possibilities are live for a subject in a given context, the subject's remaining doxastic attitudes are adjusted as if she was conditionalising on those live possibilities. This implies that the consideration of belief-forming methods' fallibility would affect a very large number of beliefs, i.e. all beliefs that one takes to be formed by relying on that method, and the subject's credences in all those beliefs would fall below one. Hence, COS predicts that the subject would stop believing all those propositions formed via that method in the moment in which she acknowledged the method's fallibility. However, this is clearly not the case. We don't abandon all beliefs that we take to be formed on the basis of a certain method such as perception by simply realising that the method is fallible. ${ }^{14}$

In contrast, TCS and the threshold view in general can easily accommodate the above data. According to TCS, one can continue believing $p$ as long as one's credence in possibilities that one takes to entail not- $p$ does not pass a certain threshold. Thus, it's coherent for TCS that a thinker can believe $p$ while at the same time assigning a minimal probability to certain error possibilities that she takes to entail not- $p$.

\subsection{Beliefs with different strengths}

${ }^{13}$ For a similar observation applied to assertibility see Worsnip (2016: 555). Note that while Worsnip is mainly concerned with assertions, my objection concerns the compatibility of belief and certain error possibilities at the psychological level.

${ }^{14}$ The inconsistency between acknowledging one's fallibility and maintaining relevant ordinary beliefs may be conceived as a specific version of the preface paradox. According to one approach to the paradox suggested by Clarke (2017), there's a shift of context between acknowledging the preface and considering a specific claim in the book. Very general error possibilities are live in the preface context but not the book context. Therefore, relative to the preface context the author believes that there are errors in the book, and does not believe any of the claims in the book. Similarly, in response to my challenge, Clarke may suggest a context shift between acknowledging one's fallibility and entertaining a particular ordinary belief. One difficulty with this account is that, while some may find it acceptable that when one considers the preface one suspends judgments on all claims in the book, it is less plausible that when one considers a method's fallibility one suspends all beliefs formed through that method. Another difficulty is that this account presupposes an implausibly neat distinction between the preface and the book context: it seems perfectly fine to say things like 'Yes, yes, it's possible that some of the historical records are mistaken' and then go on to make claims based on historical records. Such combinations of claims can be present even in the same sentence (and thus in the same context): 'The Roman Empire fell in 476AD, yet it's possible that some of the historical records are mistaken'. 
Full beliefs come in different degrees. We believe many things, but we don't believe them with the same strength. We are more confident in some of them than in others. For example, although I believe both that one plus one equals two and that my partner was a good football player before we met, I am more confident of the former than the latter. Moreover, if someone already outright believes $p$, but acquires new evidence for it, her confidence in the belief naturally rises to a higher degree. This indicates that the degree of confidence in an outright belief can be less than maximal, and thus that beliefs come in different degrees.

Clarke $(2013, \$ 7.3)$ claims that both COS and the threshold view are able to accommodate the above platitude. Nonetheless, although COS can explain degrees of partial belief in terms of degrees of credence falling short of credence one, the view cannot explain degrees of full beliefs in the same way. According to COS, one's credences in all one's beliefs have the maximal degree, i.e. one. Thus COSists cannot explain the different strengths of outright beliefs in terms of variations in credence. This doesn't mean that there are no ways in which they can explain this phenomenon. Clarke (2013 p. 11) suggests that the fact that one is more confident in some beliefs than in others is reflected in the stability of one's opinion. Beliefs held more firmly are more likely to be maintained in stringent or demanding contexts where spaces of relevant doxastic possibilities are larger, while beliefs held with less conviction are more likely to be lost in those contexts. Therefore, in general the former type of belief is stabler across context-shifts than the latter.

The problem with this account is that it introduces a distinction between two completely different types of confidence, degrees of credence and counterfactual belief status, which seems to be ad hoc, not independently motivated. First, there seems to be no ambiguity in the notion of confidence when it is used for degrees of full belief and when it is used for degrees of partial belief. The thesis that 'confidence' is ambiguous between different senses doesn't seem to have any ordinary language basis. This word doesn't pass any of the standard tests for ambiguity discussed by philosophers and linguists. Let us consider one such test by way of example. According to the 'contradiction' test, embedding an ambiguous term A (such as 'bank') in a sentence of the form 'This is A but it is not A' may sound awkward but it doesn't sound contradictory. Now consider the sentence 'Mary is confident that $p$ but is not confident that $p$ '. It seems pretty clear that this sentence has no non-contradictory readings. Thus 'confidence' doesn't pass the 'contradiction' test for ambiguous terms. ${ }^{15}$

Second, from a phenomenological point of view, degrees of confidence in full and partial beliefs seem to be the same type of thing. Intuitively, my feeling of being more confident that one plus one equals two than that my partner was a good football player before we ever met (two outright beliefs) is of the same kind than my feeling of being more confident that Donald Trump will be impeached than that I will not catch a cold more than twice during the next year (two propositions in which I am pretty confident but do not fully believe). The above considerations indicate that it is wrong to distinguish two kinds of confidence, one referring to degrees of credence and the other to the counterfactual stability of doxastic attitudes. The standard notion of confidence that applies to degrees of partial belief is extensible to degrees of outright belief as well. But if the former is reducible to comparative degrees of probability, it is plausible that the latter is as well.

${ }^{15}$ For a list of other ambiguity tests see Sennet (2016: \$4). 
In this regard, the threshold view and TCS clearly have an advantage over COS, for they provide a unified account of degrees of beliefs (both full and partial) in terms of degrees of credence. In this picture, degrees of credence match with degrees of belief across the whole spectrum from negative to positive absolute certainty, adhering to the semantic unity of confidence ascriptions and our ordinary phenomenological intuitions about confidence.

\subsection{Beliefs of unconscious subjects}

People have beliefs even when they are temporarily unconscious. For instance, it is natural to think that my partner believes that two plus two equals four also when asleep. Can COS accommodate this property of belief?

Recall that according to COS, belief is a three-place relation between a believer, a proposition and a context, where the context is determined by the space of live possibilities, i.e., the possibilities that the subject currently considers. Since there are no live possibilities for unconscious and dreamless sleeping subjects, in such cases the sort of context required for belief by COS seems to be absent.

COSists could adopt one of the following two interpretations of unconscious subjects' doxastic life. First, they could say that since an unconscious subject is currently not entertaining any possibility, the context is indeed absent. Since the existence of a context is a necessary condition for having beliefs, a subject doesn't have any belief as long as she is not conscious. Alternatively, the COSist may conceive the context of an unconscious subject as constituted by an empty set. Since according to COS, believing $p$ is taking $p$ to be true across the whole set of relevant doxastic possibilities, and every proposition would be counted as true across an empty set of possibilities, it follows that an unconscious subject believes every proposition. ${ }^{16}$

Both diagnoses seem to be highly problematic. It seems utterly absurd to think that an unconscious subject somehow believes everything-including every contradiction or absurd proposition. It seems wrong to think of sleeping people as radically irrational in this way. As for the diagnosis that unconscious subjects don't have any belief at all, this is very counterintuitive and conflicts with all the main theories of belief in philosophy of mind, including mainstream theories such as representationalism and functionalism. According to representationalism, to have a belief is to stand in a particular relation to a mental representation. A mental representation is some mental structure instantiated somewhere in the mind or brain and is poised to perform certain (typically computational) functions within the mind that often bear only remote connections to stimuli, behaviour, and phenomenology. In this picture, being temporarily unconscious presumably won't have any significant impact on the existence of mental representations. Unconscious subjects should be counted as maintaining at least most beliefs during temporary unconsciousness. Functionalists hold that having a belief is to be in a state that exhibits certain functional roles, i.e. specific actual and potential causal relations to sensory stimulations, behaviours, and other mental states. Again, being temporarily unconscious presumably doesn't affect the potential manifestation of relevant functional roles characteristic of beliefs under the right triggering conditions. Thus, according to functionalism, unconscious subjects have beliefs as well.

${ }^{16}$ Note that this applies not only to those who are merely temporarily unconscious, but also to those who are long-term or even permanently unconscious—at least as long as they have a mind. 
These issues actually extend over a much wider range, since the problem of indeterminate contexts is not merely confined to cases of unconscious subjects. Live error possibilities require those possibilities to be brought into the subject's working memory and trigger controlled cognitive processing as opposed to automatic or heuristic modes. However, we form many of our beliefs in an immediate and spontaneous way without triggering any deliberative process. In other words, in many ordinary cases we form beliefs in circumstances in which the type of context required by COS would be undefined.

In contrast, TCS has no problem in accommodating beliefs of unconscious subjects and beliefs formed subconsciously. This is because for TCS there is nothing like a doxastic context constitutive of the metaphysical nature of belief and determined by the space of salient error possibilities. According to TCS, contextual factors can contingently affect degrees of confidence by modifying credence distributions, but such factors are not supposed to be metaphysical constituents of doxastic attitudes. Thus subjects can maintain their degrees of credence and beliefs when they are unconscious or asleep.

\section{The lottery problem}

So far I have assessed COS and TCS against a series of features of belief. While TCS can easily accommodate all of them, COS has either difficulties or disadvantages in explaining the data. This provides at least some prima facie reasons in favour of TCS over COS. However, as argued by Clarke (2013), Greco (2015) and Dodd (2017), COS seems to be better positioned than the threshold view in accommodating some other important features of belief. In particular, it has been argued that COS can accommodate the fact that it is possible (and indeed quite common) for one not to believe that one's lottery ticket in a fair lottery is a loser despite the very high likelihood of it being a loser, while TCS cannot. ${ }^{17}$ Suppose that you own a lottery ticket that is part of a fair lottery of $n$ tickets. Your credence that your ticket is a loser is thus $\frac{n-1}{n}$. On the standard threshold view, belief is reducible to degrees of credence above a certain threshold.

${ }^{17}$ I focus here on what I consider the most important (alleged) explanatory advantage of COS over TCS. Unfortunately, for reasons of space here I cannot provide a full discussion of other alleged advantages of COS. One such advantage is that COS would provide a simpler explanation of a range of qualitative dispositions involved in believing $p$, such as the commitment to the truth of $p$ and taking $p$ for granted in reasoning in appropriate circumstances. The challenge for the threshold view is to explain how changes of credence that just falls short of the threshold level do not make any qualitative difference to one's dispositions while changes crossing the threshold level do. COS can easily avoid this problem. Having credence one in $p$ implies that one excludes all possibilities one takes to be incompatible with $p$. Hence a belief that $p$ completely commits one to the truth of $p$ and to take $p$ for granted in reasoning. An antireductionism version of TCS could solve the problem by appealing to the phenomenon of 'cognitive closure', a new feature causally produced by high credence but not constituted by it. When one's credence in $p$ is high enough, as a psychological fact, one closes her mind on whether $p$ and discounts possibilities entailing not- $p$. See Weisberg (forthcoming, \$3) for detailed discussion and Tang (2015) for a similar solution. This solution also addresses the arbitrariness problem for determining the threshold: since the threshold should be the point at which qualitative dispositions emerges as a result of a certain high degree of credence. See Gao (2016: Ch.5, \$1) for further discussion of these issues. 
Thus, if $n$ is sufficiently high, it is impossible for you not to believe that your ticket will lose before knowing the result, which is strikingly counterintuitive. The same problem doesn't directly apply to TCS, for this view is neutral on whether belief can be fully reduced to credence above a certain threshold or not. However, I take it as a challenge for TCS to explain how it is possible for someone not to believe that her lottery ticket is a loser in these circumstances.

A possible solution could appeal to psychological heuristics. As argued by Nagel (2011), the presentation of numerical odds in the lottery would trigger controlled processing as opposed to the automatic and heuristic cognitive mode (ibid.: 11). Importantly, according to Nagel, different cognitive modes of presentation can deliver different reactions to the same proposition. In cases where questions on whether a certain lottery proposition is true are made explicit in reasoning, presumably the triggered controlled reasoning in cognition processing inhibits or defeats the use of heuristics responsible for the formation of outright beliefs. Hence it is possible for one to refrain from believing the lottery proposition in such situations.

Another way to respond to the challenge is to distinguish credence from different mental attitudes such as probability estimates: while the latter attitudes would be exclusively influenced by statistical evidence, the former should be at least partially informed by non-statistical features of evidence (Fassio \& Gao forthcoming, Smith 2016). Thus in the lottery case, although the probability estimate of my ticket being a loser is very high, normal people tend not to consider the estimate alone as sufficient to constitute a proper basis for forming a full belief. ${ }^{18}$

While TCS seems to have the resources to meet the challenge accommodating doxastic attitudes about lotteries, it is important to observe that lottery cases are also problematic for COS-indeed I would say even more problematic for COS than TCS. A number of philosophers have argued that it is perfectly possible (and even rational) to believe that one's lottery ticket will lose (see e.g. McGlynn 2013; Reed 2010). However, according to COS, one believes $p$ only if one's credence in $p$ is one. It follows that, if someone accepts that the lottery is fair, and thus that there is a very small chance of winning, it is impossible (not merely irrational) for her to believe that her ticket is a loser. COS must thus conclude that all people who think to have outright beliefs that their tickets in a fair lottery are losers (including a notable number of philosophers and myself) are actually wrong about their own mental states on the matter. This seems a seriously problematic consequence of COS, even worse than that faced by TCS. The latter view can deploy one of the possible solutions considered above in explaining why someone could not believe that her lottery ticket is a loser, while also allowing the possibility of believing that one's lottery ticket is a loser. ${ }^{19}$

${ }^{18}$ It is also worth noting that, while the lottery paradox seems to favor the credence-one view over the threshold view, other structurally similar paradoxes seem rather to support the opposite conclusion. A notable example is the preface paradox (Makinson 1965). According to this paradox, it seems reasonable to believe a long list of propositions but not their conjunction. COS and the credence-one view entail closure of one's beliefs, and thus are incompatible with the possibility of not believing the conjunction. On the contrary, the threshold view can easily explain the conjunction failure in terms of the small uncertainty attached to each proposition in the list, which leads to a much higher accumulated risk of error in the conjunction. However, see Clarke (2017) for a COSist response to this challenge.

19 According to TCS, full belief is compatible with entertaining certain error possibilities (see \$3.1). Believing that one's ticket is a loser while upholding a minimal credence that one could win the lottery is just another example of such cases. 


\section{Conclusion}

In this paper, I have considered two competing versions of credal sensitivism, COS and TCS. I have argued that COS faces serious problems in accommodating a range of important facts about beliefs. TCS is not affected by any such problem. I have then considered an alleged advantage of COS over TCS and argued that, far from being decisive, this may rather be a further problem for COS. Although the above considerations may not conclusively establish the superiority of TCS over COS, I hope I have shown that on balance TCS fares better than COS on a number of points. This should provide at least prima facie reasons for favouring TCS over COS.

Although the paper has initially been structured as concerning an in-house debate amongst upholders of doxastic sensitivism, some of the arguments in the paper can be considered as independently addressing the more general dispute between the credence-one view and the threshold view. More specifically, the paper addresses the dispute by comparing the most plausible form of the credence-one view (COS) and a non-standard version of the threshold view (TCS). Thus, another important conclusion we can draw from my discussions is that contrary to what advocates of COS have claimed, we have good reasons to abandon the credence-one view once and for all and to embrace some version of the threshold view.

\section{Reference}

Adler, Jonathan E. 2012. "Contextualism and Fallibility: Pragmatic Encroachment, Possibility, and Strength of Epistemic Position." Synthese 188 (2): 242-72.

Bach, Kent. 2005. "The Emperor's New 'Knows." In Contextualism in Philosophy: Knowledge, Meaning, and Truth, edited by Gerhard Preyer and Georg Peter, 51-89. Oxford: Oxford University Press.

Clarke, Roger. forthcoming. "Assertion, Belief, and Context." Synthese, 1-27.

- 2013. "Belief Is Credence One (in Context)." Philosopher's Imprint 13 (11): 1-18.

- 2018. "Assertion, Belief, and Context." Synthese 195 (11): 4951-77.

Dodd, Dylan. 2017. "Belief and Certainty." Synthese 194: 4597-4621.

Dougherty, Trent, and Patrick Rysiew. 2009. "Fallibilism, Epistemic Possibility, and Concessive Knowledge Attributions." Philosophy and Phenomenological Research 78 (1): 128-32.

Fantl, Jeremy, and Matthew McGrath. 2009. Knowledge in an Uncertain World. Oxford: Oxford University Press.

Fassio, Davide, \& Gao, Jie. (forthcoming). "Belief, Credence and Statistical Evidence." Theoria.

Gao, Jie. (2016). Belief, Knowledge and Action. Dissertation, University of Edinburgh.

Gao, Jie. (2019). “Credal Pragmatism.” Philosophical Studies, 176, 1595-1617.

Ganson, Dorit. 2008. "Evidentialism and Pragmatic Constraints on Outright Belief." Philosophical Studies 139 (3): 441-58.

Gerken, Mikkel. 2011. "Warrant and Action.” Synthese 178 (3): 529-47.

- 2012. "On the Cognitive Bases of Knowledge Ascriptions." In Knowledge Ascriptions, edited by Jessica Brown and Mikkel Gerken. Oxford University Press.

. 2017. On Folk Epistemology. Oxford University Press.

Greco, Daniel. 2015. "How I Learned to Stop Worrying and Love Probability One." Philosophical Perspectives 29 (1): 179-201.

Hawthorne, John. 2004. Knowledge and Lotteries. Oxford: Oxford University Press. 
Jackson, Elizabeth. forthcoming. "How Belief-Credence Daulism Explains Away Pragmatic Encroachment." Philosophical Quarterly

Kruglanski, Arie W, and Donna M. Webster. 1991. “Group Members' Reactions to Opinion Deviates and Conformists at Varying Degrees of Proximity to Decision Deadline and of Environmental Noise." Journal of Personality and Social Psychology 61 (2): 212-25.

Kruglanski, Arie W., and Donna M. Webster. 1996. "Motivated Closing of the Mind: 'Seizing' and 'Freezing."' Psychological Review 103 (2): 263.

Kruglanski, Arie W, Donna M. Webster, and Adena Klem. 1993. "Motivated Resistance and Openness to Persuasion in the Presence or Absence of Prior Information." Journal of Personality and Social Psychology 65 (5): 861-76.

Kyburg, Henry E. 1983. "Rational Belief." Behavioral and Brain Sciences 6 (2): 231-43.

MacFarlane, John. 2005. "The Assessment Sensitivity of Knowledge Attribution." In Oxford Studies in Epistemology, edited by Tamar Gendler and John Hawthorne, 197-234. Oxford: Oxford University Press.

Makinson, David C. 1965. "The Paradox of the Preface." Analysis 25 (6): 205-7.

Mayseless, Ofra, and Arie W Kruglanski. 1987. "What Makes You so Sure? Effects of Epistemic Motivations on Judgmental Confidence." Organizational Behavior and Human Decision Processes 39 (2): 162-83.

McGlynn, Aidan. 2013. "Believing Things Unknown.” Noûs 47 (2): 385-407.

Nagel, Jennifer. 2008. "Knowledge Ascriptions and the Psychological Consequences of Changing Stakes." Australasian Journal of Philosophy 86 (2): 279-94.

. 2010. "Epistemic Anxiety and Adaptive Invariantism." Philosophical Perspectives 24 (1): 407-35.

2011. 'The Psychological Basis of the Harman-Vogel Paradox." Philosophers' Imprint 11 (5): $1-28$.

Norby, Aaron. 2015. “Uncertainty without All the Doubt." Mind and Language 30 (1): 70-94.

Reed, Baron. 2010. "A Defense of Stable Invariantism.” Nô̂s 44 (2): 224-44.

Ross, Jacob, and Mark Schroeder. 2014. "Belief, Credence, and Pragmatic Encroachment." Philosophy and Phenomenological Research 88 (2): 259-88.

Sennet, Adam. 2016. "Ambiguity." Edited by Edward N. Zalta. The Stanford Encyclopedia of Philosophy.

Smith, Martin. 2016. Between Probability and Certainty. Oxford: Oxford University Press.

Sturgeon, Scott. 2008. "Reason and the Grain of Belief." Noûs 42 (1): 139-65.

Tang, Weng Hong. 2015. "Belief and Cognitive Limitations." Philosophical Studies 172 (1): 249-60.

Weatherson, Brian. 2005. "Can We Do without Pragmatic Encroachment?" Philosophical Perspectives 19 (1): 417-43.

Webster, Donna M. 1993. "Motivated Augmentation and Reduction of the Overattribution Bias." Journal of Personality and Social Psychology 65 (2): 261-71.

Weisberg, Jonathan. forthcoming. "Belief in Psyontology." Philosopher's Imprint

Worsnip, Alex. 2016. "Belief, Credence, and the Preface Paradox." Australasian Journal of Philosophy 94 (3): 549-62. 